\title{
Miniaturized Wideband Microstrip Antenna for Recent Wireless Applications
}

\author{
Shereen A. Shandal' ${ }^{1}$, Yaqeen S. Mezaal' ${ }^{2}$, Mahmood F. Mosleh ${ }^{1}$, Mohammed A. Kadim ${ }^{3}$ \\ ${ }^{1}$ Electrical Engineering Technical College, Middle Technical University, Baghdad, Iraq \\ ${ }^{2}$ Medical Instrumentation Engineering Department, Al-Esraa University College, Baghdad, Iraq \\ ${ }^{3}$ Institute of Technology, Middle Technical University, Baghdad, Iraq \\ *corresponding author, E-mail: yakeen_sbah@yahoo.com
}

\begin{abstract}
In this paper, a pentagon slot inside fractal circular patch microstrip resonator to design compact antenna over partial ground plane is introduced using $3^{\text {rd }}$ iteration of adopted fractal geometry. This antenna is modeled on FR4 substrate with a size of $(20 \times 18) \mathrm{mm}^{2}$, thickness of $1.5 \mathrm{~mm}$, permittivity of 4.3 and loss tangent of 0.02 . The used type of feeding is microstrip line feed. It is designed to operate at wide frequency range of $(4.5-9.3) \mathrm{GHz}$ at resonant frequencies of $5.7 \mathrm{GHz}$ and $7.9 \mathrm{GHz}$ with impedance bandwidth of $4.8 \mathrm{GHz}$. Both lengths of ground plane $L_{g}$ and width of feed line $W_{f}$ are optimized in order to acquire optimum bandwidth. The simulated return loss values are 33 and $-41 \mathrm{~dB}$ at two resonant frequencies of 5.7 and $7.9 \mathrm{GHz}$ with gain of $3.2 \mathrm{~dB}$. The simulated results offered acceptable compatibility with measured results. Also, the proposed wideband microstrip antenna has substantial compactness that can be integrated within numerous wireless devices and systems.
\end{abstract}

Keywords - Fractal microstrip antenna; pentagon slot; Cband; Partial ground plane; compactness.

\section{Introduction}

Recently, wireless communication system has testified enormous expansions and augmentation in the request for high data rate through wide bandwidth, consequently Micro Strip Antenna (MSA) is used to meet that demand [1]. There are a large number of MSAs developed for indoor and outdoor communications and Radar applications [2]. The most important features of MSA that considered as challenge for researchers are size compactness, ease of fabrication, low cost and light weight. Also, it can be simply incorporated on Printed Circuit Board (PCB) [3]. However, MSA has drawbacks of narrow bandwidth and low gain. Thus, the shape of MSA needs to be changed by using a fractal geometry technique [4]. Fractal MSA is principally used to improve the antenna electrical parameters such as bandwidth, input reflection and gain in addition to size reduction [5]. The form of fractal MSA seems either random or deterministic. Random fractal is constituted randomly

configuration of a miniature wideband circular polarization microstrip fractal antenna is introduced in [13] for wideband from a set of non-determined steps and its shapes are taken from nature such as tree fractal antenna. Deterministic fractal has been produced as a result of an iterative common types of fractal MSA such as Koch, Sierpinski, Hillbert, Minkowski and Cantor. There are two substantial properties of fractal MSA that are space filling and self-similarity properties $[6,7]$. Space filling can be used for size reduction and enlarge the operative current length of MSA by the iteration number intensification under the same area, while self-similarity can be exploited for designing dual or multiple band microstrip antennas. On the other hand, fractal geometries can be used to design a variety of wideband and ultra-wideband microstrip antennas as reported in [8-13] using different methodologies.

In [8], symmetrical slot geometries were employed to design broadband microstrip antenna. Its performance had been realized by merging diverse downscaled varieties of a configuration of "island-like" space-filling slot antennas without changing the total antenna size. Correspondingly, symmetric slots have been used to enhance the axial bandwidth for microstrip fractal antennas reported in[9] to acquire circular polarization performance. In [10], a miniature wideband fractal MSA for wireless applications was proposed using circle inscribed octagon and Coplanar Waveguide (CPW) feed. It uses FR4 substrate with dimensions of $(60 \times 60) \mathrm{mm}^{2}$. This proposed design has been investigated up to three iterations. Full ground plane is used with thickness of $1 \mathrm{~mm}$. Simulation results indicate that this antenna has a various resonance frequencies with various frequency ranges. This antenna is relevant for satellite communications and radio communications. In [11], a pentagon fractal antenna for above $6 \mathrm{GHz}$ band applications was designed using coaxial feed. This antenna is appropriate for applications in fixed wireless systems. Koch fractal based hexagonal patch antenna for circular polarization has been designed for ultra-wideband application as explained by [12] using microstrip inset feed and a combination of two fractal geometries of Koch and Sierpinski. Partial rectangular shape ground plane has been employed to acquire wider bandwidth. This MSA is appropriate for $\mathrm{C}$ and $\mathrm{X}$ frequency band applications under IEEE and Multimedia standards. An embedded

applications. The suggested design has a Spidron fractal slot with a supplementary rectangular slit and an embedded 
Spidron fractal patch. A microstrip tapered feedline is organized for the excitation and alleviating of hybrid coupler.

This study presents the design of highly compact fractal MSA for wideband applications and investigates the advantages of circular patch with a slot of pentagon shape up to three iteration levels. To reach an optimum bandwidth, two techniques are used as in fractal geometry technique and partial ground plane with rectangular shape. The design of optimal iteration design has been successfully simulated and fabricated with very electrical specifications. The measured results agree well with the simulations.

\section{Design Concept}

The conventional construction of MSA is shown in Figure1. It mainly consists of top, substrate and bottom layers. The top layer mainly comprises two parts; the first one is called patch that may take any possible geometric shape and the second one is called microstrip feed line. This layer is photo engraved on substrate [14]. The most common used type of substrate layer is FR4 since it is widely available in the market and has low value of loss tangent. The performance of antenna can be improved by controlling the thickness of substrate $h$, so that it is considered as principal factor for determining antenna performance. Using thicker substrate with low permittivity value $\epsilon_{r}$ makes antenna parameters improved, but at the same time it has a drawback of increased antenna size. Therefore, a tradeoff should be made between antenna performance and antenna dimensions [15]. The last layer of MSA is called bottom or ground plane layer. It may take any form and it can be utilized as full or partial ground plane. It plays a vital role to enhance the bandwidth of MSA.

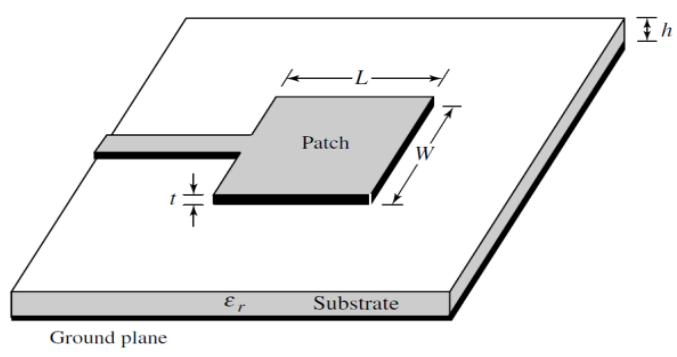

Figure 1 Components of MSA

The proposed model is designed based on iterative method using only three iterations. Higher iteration numbers make the antenna parameters not modified straightforwardly and increase the complexity of fabrication process as the iteration number increases. The design concept is based on "Trial and Error" principle for reaching to desired resonant frequency according to dimensions scaling of proposed antenna structure as similar as antenna design principles reported in $[1,5$, and 14]. FR4 substrate has been used in antenna design with $\in_{r}=4.3$ and $h=1.5 \mathrm{~mm}$. Initially, patch circular base radius $R_{l}$ has been chosen based on desired fundamental resonance, which can be calculated based on [14] by:

$\mathrm{R}_{1}=\frac{f}{\left\{1+\frac{2 h}{\pi \epsilon_{r} f}\left[\ln \left(\frac{\pi f}{2 h}\right)+1.7726\right]\right\}^{1 / 2}}$
Where $h$ is thickness of substrate, $\in_{r}$ is a permittivity, $f$ is a fundamental resonance frequency.

The determined radius $R_{1}$ of proposed model is equal to $7.5 \mathrm{~mm}$ which represents the base circular patch or zero iteration as shown in Figure 2 (a).

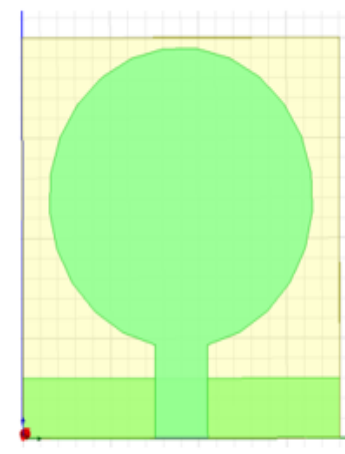

(a)

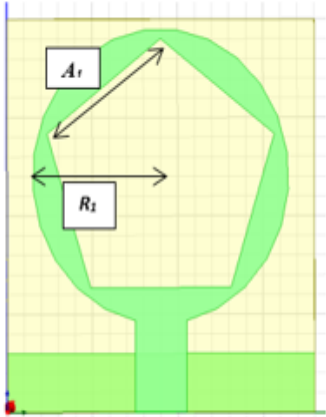

(b)
Figure 2 (a) Zeroth Iteration and (b) First Iteration

Based on [16], the side length of pentagon slot $A_{k}$ can be found by :

$A_{k}=R_{K} * \sqrt{\frac{5-\sqrt{5}}{2}}$

Where $k=1,2,3$ (iteration index) and $R_{k}$ represents the radius of three circles, $R_{1}, R_{2}$ and $R_{3}$. The second step is etching a regular pentagon slot with estimated side length A1( by Trial and Error ) of $8.22 \mathrm{~mm}$ in order to obtain the first iteration that is shown in Figure 2 (b) based on converging to fundamental resonance. The side length of the second and third pentagon is equal to 6.1 and $4.11 \mathrm{~mm}$ accordingly. Correspondingly, the area of pentagon $P_{k}$ can be found by [16]:

$P_{k}=1.7204 * A_{k}^{2}$

The area of first, second and third regular pentagon slots $P_{l}$, $P_{2}$ and $P_{3}$ are $116 \mathrm{~mm}^{2}, 65 \mathrm{~mm}^{2}$ and $29 \mathrm{~mm}^{2}$ respectively. For second iteration, a second circle with a radius of $R_{2}$ is etched inside pentagon slot frame. The radius of second circle $R_{2}$ can be calculated by :

$R_{j}=\frac{R_{i}}{S}$

Where $\mathrm{i}=1,2, j=2,3$ and $S$ is an estimated scale factor that used in this design as constant value equal to 1.3 (estimated by Trial and Error ) based on converging to fundamental resonance. Also, a second regular pentagon slot is etched inside second circle with side length of $6.17 \mathrm{~mm}$ in order to attain the second iteration. Finally, the same procedure will be repeated to obtain the third iteration by etching a regular pentagon slot with side length of $4.11 \mathrm{~mm}$ inside third circle (inner circle) with radius of $R_{3}$ equal to $4.58 \mathrm{~mm}$ that calculated by equation (4). The second iteration, third iteration and bottom views are shown in Figure 3. 


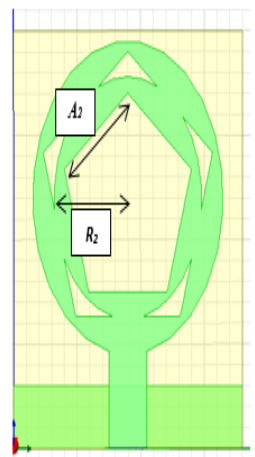

(a)

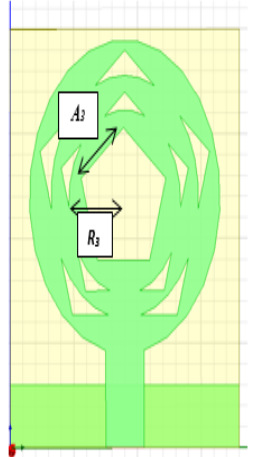

(b)

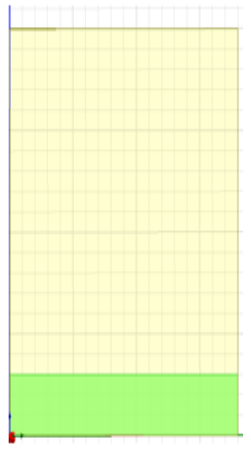

(c)
Figure 3 (a) Second iteration, (b) Third iteration(c) Bottom view

The FR4 substrate as rectangular shape of $20 \mathrm{~mm}$ length and $18 \mathrm{~mm}$ width has been used. The partial ground plane has a rectangular shape covering the feed line with a gap $g$ equal to $1.5 \mathrm{~mm}$ away from circular patch. Also, microstrip line feed is the type of feeding used in this design since it is simplest type and easy to manufacture. After optimization process, the parameters of proposed antenna are listed in Table 1. As well, the final geometrical view of proposed fractal MSA is illustrated in Figure 4.

Table 1: The parameters of proposed model.

\begin{tabular}{|c|c|c|c|}
\hline Parameter & value & parameter & Value \\
\hline Permittivity $E_{r}$ & 4.3 & Radius of first circle $R_{I}$ & $7.5 \mathrm{~mm}$ \\
\hline Thickness of substrate $h$ & $1.5 \mathrm{~mm}$ & Radius of second circle $R_{2}$ & $5.77 \mathrm{~mm}$ \\
\hline Width of substrate $W_{s}$ & $18 \mathrm{~mm}$ & Radius of third circle $R_{3}$ & $4.58 \mathrm{~mm}$ \\
\hline Length of substrate $L_{s}$ & $20 \mathrm{~mm}$ & Internal radius of pentagon $1 r_{I}$ & $5.96 \mathrm{~mm}$ \\
\hline Width of ground $W_{g}$ & $18 \mathrm{~mm}$ & Internal radius of pentagon $2 r_{2}$ & $4.55 \mathrm{~mm}$ \\
\hline Length of ground $L_{g}$ & $3 \mathrm{~mm}$ & Internal radius of pentagon3 $r_{3}$ & $2.95 \mathrm{~mm}$ \\
\hline Width of feed line $W_{f}$ & $3 \mathrm{~mm}$ & Gap between ground and patch $g$ & $1.5 \mathrm{~mm}$ \\
\hline Length of feed line $L_{f}$ & $4.65 \mathrm{~mm}$ & Side of inner pentagon $A_{3}$ & $4.11 \mathrm{~mm}$ \\
\hline
\end{tabular}

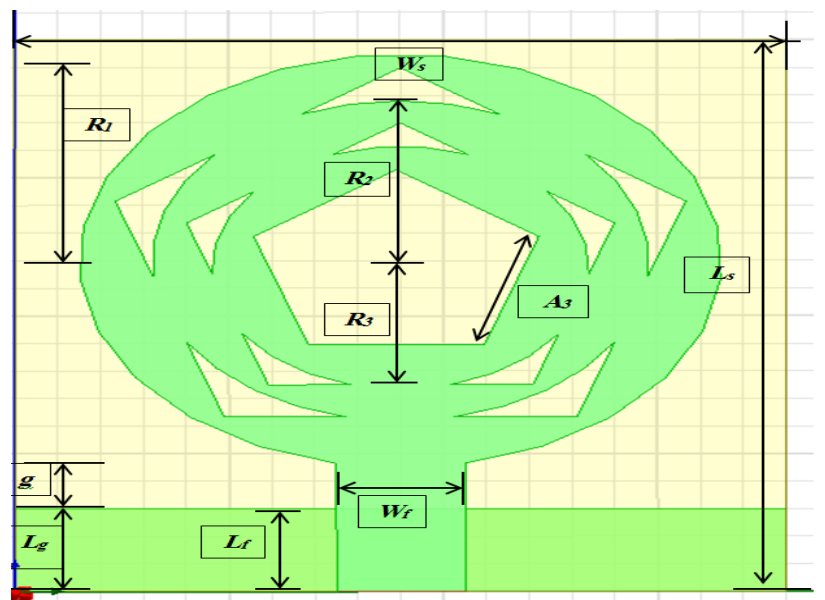

Figure 4 Geometrical view of projected fractal MSA

\section{Simulation results and discussion}

The proposed model has been designed and simulated by using Finite Element Method (FEM) based on HFSS version 2014. A comparison between different iterations is listed in Table 2.

Table 2: Comparison of proposed model based on various iteration numbers.

\begin{tabular}{|c|c|c|c|c|c|}
\hline $\begin{array}{c}\text { Iteration } \\
\text { no. }\end{array}$ & $\begin{array}{c}\mathrm{S} 1.1 \\
(\mathrm{~dB})\end{array}$ & $\begin{array}{c}\text { Resonance } \\
\text { frequency } \\
(\mathrm{GHz})\end{array}$ & $\begin{array}{c}\text { Impedance } \\
\text { bandwidth }\end{array}$ & $\begin{array}{c}\text { Radiation } \\
\text { efficiency }\end{array}$ & $\begin{array}{c}\text { Gain } \\
(\mathrm{dB})\end{array}$ \\
\hline 1st & -38.3 & 4.5 & $17.7 \%$ & $89.13 \%$ & 3.48 \\
\hline 2nd & -40.5 & 5.2 & $64.7 \%$ & $95.4 \%$ & 3.48 \\
\hline $\begin{array}{c}\text { 3rd } \\
\text { (Proposed) }\end{array}$ & $-33,-41$ & $5.7,7.9$ & $70 \%$ & $97 \%$ & 3.10 \\
\hline
\end{tabular}

It is obvious that at third iteration, the best return loss $\mathrm{S} 1.1$ values are equal to -33 and $-41 \mathrm{~dB}$ at two resonance frequencies of 5.7 and $7.9 \mathrm{GHz}$ with the widest bandwidth among other iterations. Also, a comparison of return loss S1.1 at various frequencies for various iteration numbers is shown in Figure 5.

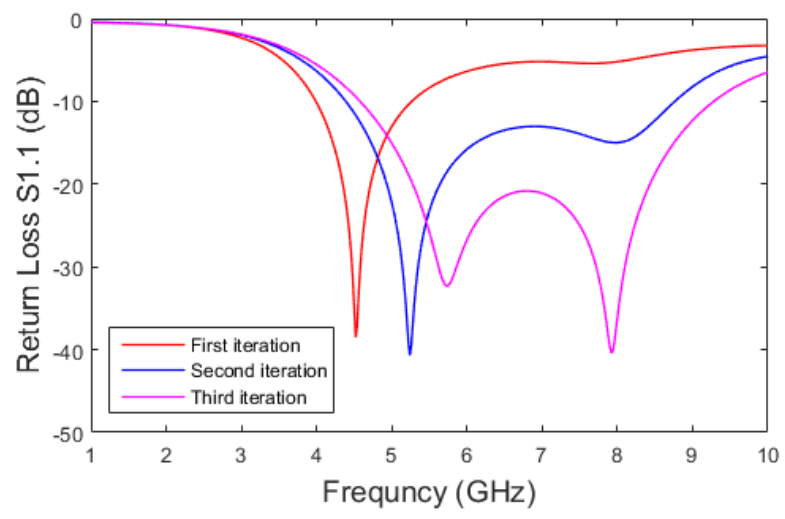

Figure 5 Simulated Return Loss S1.1 for Various Iterations No.

The parametric investigations of ground plane length $L_{g}$ is used to show the effect of $L_{g}$ variation on the performance of proposed model. At first, the length of feed is adjusted to 2 $\mathrm{mm}$ and increased by $0.5 \mathrm{~mm}$ up to $4 \mathrm{~mm}$. It is obvious that excellent impedance matching can be obtained when $L_{g}$ equals to $3 \mathrm{~mm}$. The results are summarized in Table 3 . A comparison of return loss at various frequencies for different values of $L_{g}$ is shown in Figure 6. 
Table 3: Comparison of proposed model based on $L_{g}$.

\begin{tabular}{|c|c|c|c|c|c|}
\hline $\begin{array}{c}\text { Length of } \\
\text { ground }(L g)\end{array}$ & $\mathrm{S} 1.1(\mathrm{~dB})$ & $\begin{array}{c}\text { Resonance } \\
\text { frequency }(\mathrm{GHz})\end{array}$ & $\begin{array}{l}\text { Impedance } \\
\text { bandwidth }\end{array}$ & $\begin{array}{c}\text { Radiation } \\
\text { efficiency }\end{array}$ & $\begin{array}{c}\text { Gain } \\
(\mathrm{dB})\end{array}$ \\
\hline $2 \mathrm{~mm}$ & $\begin{array}{c}(-23.4,- \\
17.6)\end{array}$ & $(5.2,7.6)$ & $64.41 \%$ & $96.9 \%$ & 3.02 \\
\hline $2.5 \mathrm{~mm}$ & $(-26,-21)$ & $(5.4,7.7)$ & $66.17 \%$ & $97 \%$ & 3.04 \\
\hline $\begin{array}{c}3 \mathrm{~mm} \\
\text { Proposed })\end{array}$ & $(-33,-41)$ & $(5.7,7.9$ & $70 \%$ & $97 \%$ & 3.10 \\
\hline $3.5 \mathrm{~mm}$ & $\begin{array}{c}(-27.5,- \\
27.8)\end{array}$ & $(5.9,8.1)$ & $69.1 \%$ & $97.4 \%$ & 3.29 \\
\hline $4 \mathrm{~mm}$ & $\begin{array}{c}(-19,- \\
20.3)\end{array}$ & $(6,8.7)$ & $73.5 \%$ & $97 \%$ & 4.37 \\
\hline
\end{tabular}

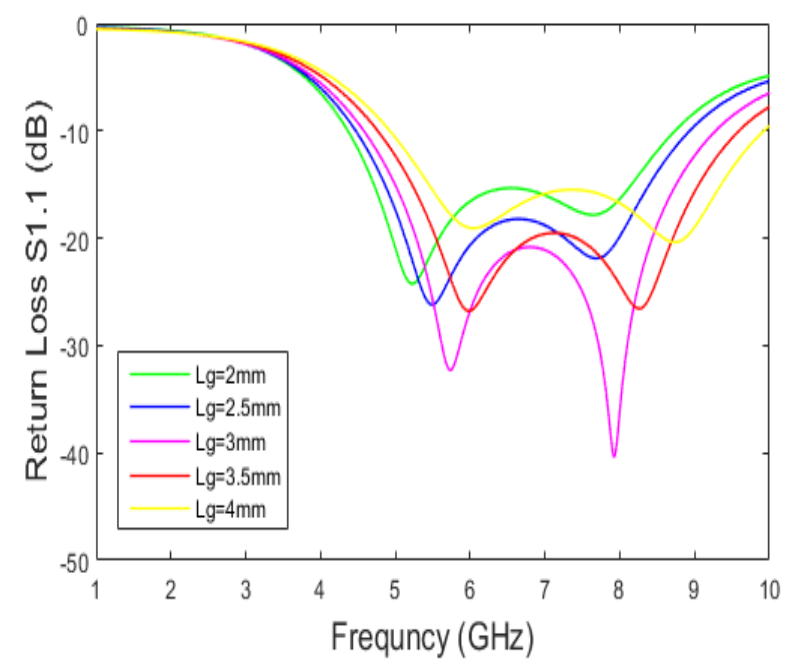

Figure 6 Simulated Return Loss S1.1 for Various Values of length of ground $L_{g}$

The width of feed line $W_{f}$ is changed tentatively to acquire wide bandwidth and show the effect of $W_{f}$ variation on the performance of proposed model. At first, the width of feed is taken $2 \mathrm{~mm}$ and increased by $0.5 \mathrm{~mm}$ until $4 \mathrm{~mm}$. It is clear that when $W_{f}$ equal to $3 \mathrm{~mm}$, the optimal return loss $\mathrm{S} 1.1$ can be observed as depicted in Table 4 . The comparison of return loss at a number of frequencies for different values of $W_{f}$ is presented in Figure 7.

Table 4: Comparison of proposed model based on $W_{f}$.

\begin{tabular}{|c|c|c|c|c|c|}
\hline $\begin{array}{c}\text { Width of } \\
\text { feed } \\
W_{f}\end{array}$ & S1.1(dB) & $\begin{array}{c}\text { Resonance } \\
\text { frequency (GHz) }\end{array}$ & $\begin{array}{c}\text { Impedance } \\
\text { bandwidth }\end{array}$ & $\begin{array}{c}\text { Radiation } \\
\text { efficiency }\end{array}$ & $\begin{array}{c}\text { Gain } \\
(\mathrm{dB})\end{array}$ \\
\hline $2 \mathrm{~mm}$ & -15 & 7 & $55.88 \%$ & $97.08 \%$ & 3.14 \\
\hline $2.5 \mathrm{~mm}$ & -28 & 7.2 & $66.17 \%$ & $97.40 \%$ & 3.13 \\
\hline $\begin{array}{c}3 \mathrm{~mm} \\
\text { (Proposed) }\end{array}$ & $(-33,-41)$ & $(5.7,7.9)$ & $70 \%$ & $97.05 \%$ & 3.10 \\
\hline $3.5 \mathrm{~mm}$ & $(-23,-23)$ & $(5.6,8.5)$ & $69.11 \%$ & $97.19 \%$ & 3.18 \\
\hline $4 \mathrm{~mm}$ & $(-18,-19)$ & $(5.5,8.6)$ & $66.17 \%$ & $96.81 \%$ & 3.25 \\
\hline
\end{tabular}

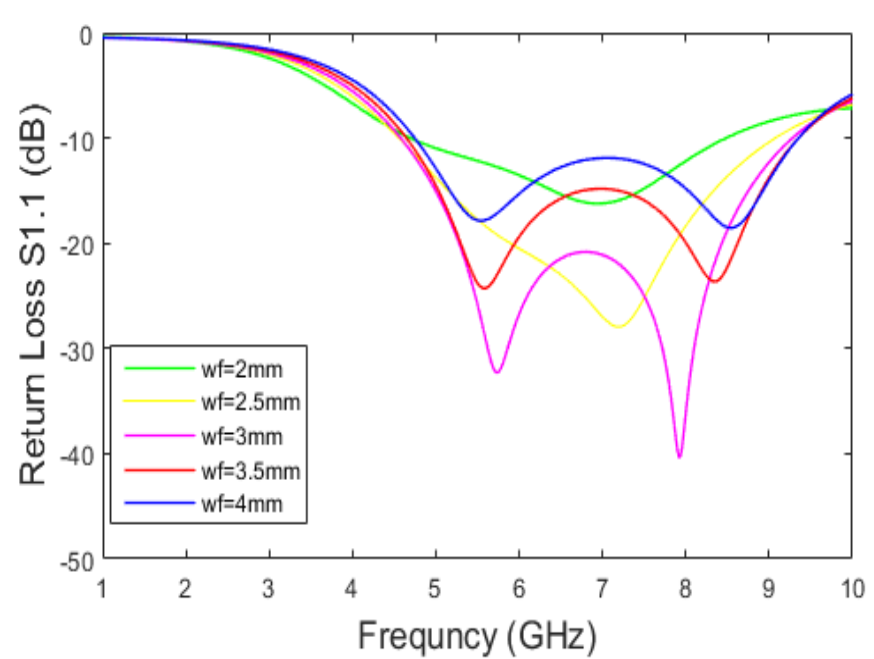

Figure 7 Simulated Return Loss S1.1 for Various Values of width of ground $W_{f}$

As depicted in the Table 5, a comparison of our work with other testified microstrip antennas in the literature has been made. The proposed antenna in this study is mostly more compact than microstrip antennas in $[12,17-20]$ in the related applications.

Table 5: Size comparison of proposed antenna with references $[12,17-20]$

\begin{tabular}{|c|c|c|}
\hline Reference & Size $\left(\mathrm{mm}^{2}\right)$ & $\begin{array}{c}\text { Resonant } \\
\text { Frequency }(\mathrm{GHz})\end{array}$ \\
\hline$[12]$ & $30 \times 35$ & $3.1 / 6.9 / 8.4 / 9.1$ \\
\hline$[17]$ & $173 \times 70$ & $3.1 / 5 / 7 / 10.6$ \\
\hline$[18]$ & $17.2 \times 20$ & $5.25 / 5.8$ \\
\hline$[19]$ & $80 \times 80$ & $4.4 / 5.5 / 6.2$ \\
\hline$[20]$ & $100 \times 100$ & 3.1 to 10.6 \\
\hline Proposed & $20 \times 18$ & $5.7 / 7.9$ \\
\hline
\end{tabular}

\section{Measurement}

After locating the finest values for fractal MSA design based on in Tables 1-4, the proposed antenna is fabricated on a substrate of FR4 with dimensions of $(20 \times 18) \mathrm{mm}^{2}$. It has been measured using Agilent $8510 \mathrm{C}$ network analyzer. The fabricated antenna is shown in Figure 8. The simulated and measured return loss S1.1 results are shown in Figure 9. 


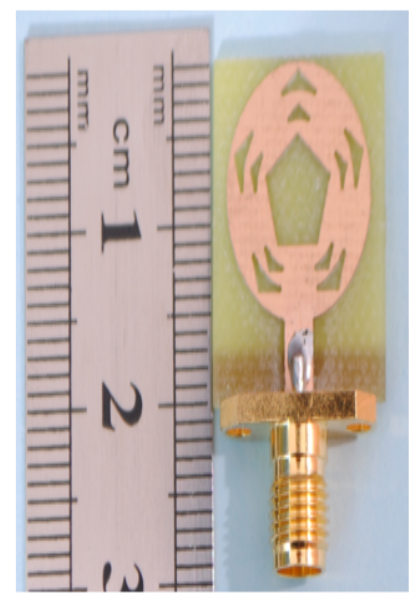

(a)

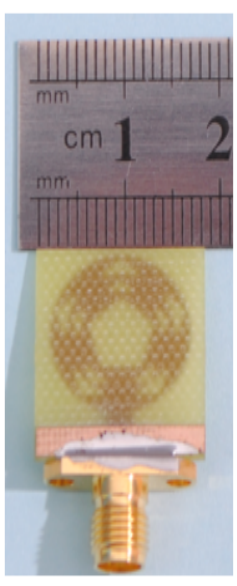

(b)
Figure 8 Fabricated Prototype of Proposed Antenna (a) Top View (b) Bottom View

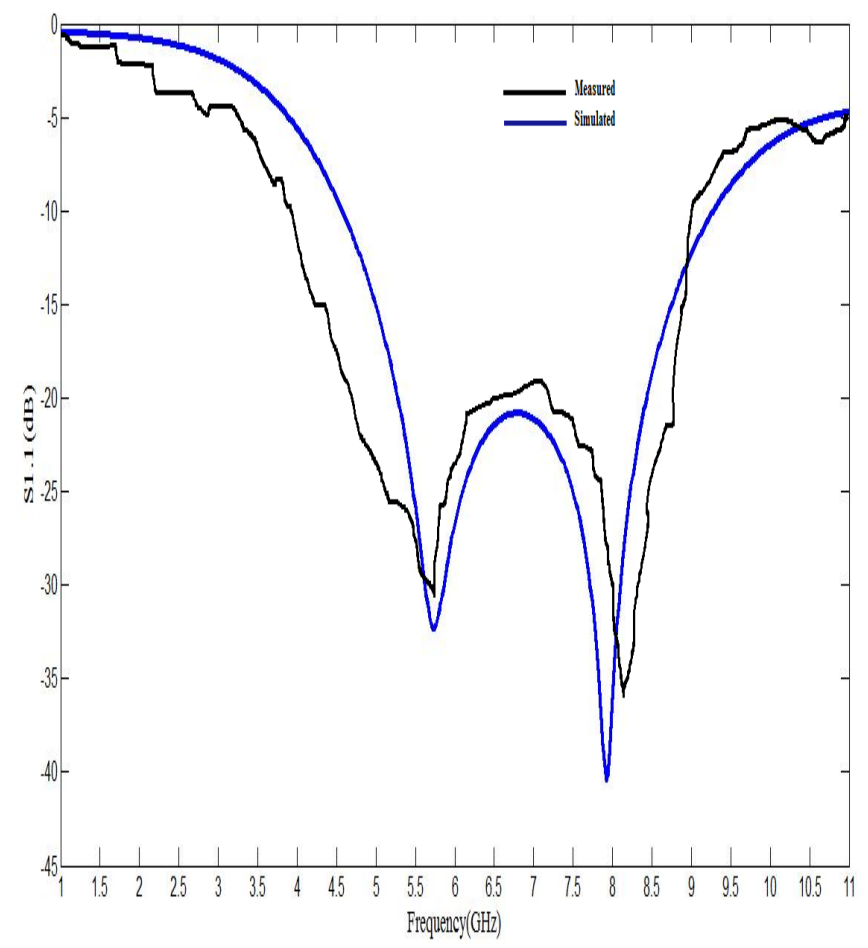

Figure 9 Simulated Return Loss as Compared with Measured Return Loss

The S1.1 responses point out an adequate agreement between simulated and measured results with slight deviations. The differences between them are attributable to SMA connector mismatches, conductor losses and fabrication tolerance.

The simulated and measured 2D Radiation patterns of proposed antenna for two resonance frequencies are shown in Figure 10. It stands for the far field radiation pattern at 5.7 and $7.9 \mathrm{GHz}$ respectively. It is clear that proposed antenna has a bi- directional radiation patterns. Useful part of radiation pattern will be raising plane for two values of phi; 0 degree for H-plane and 90 degree for E-plane. The simulations and measurements of radiation patterns are in good conformity.
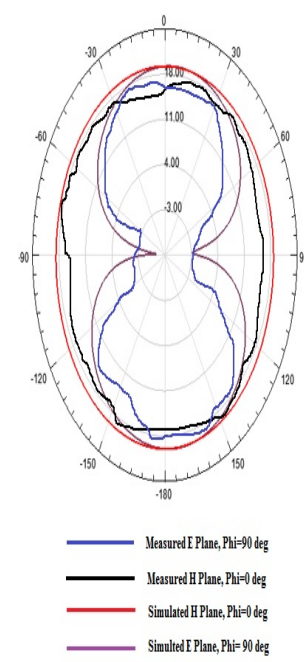

a) $5.7 \mathrm{GHz}$

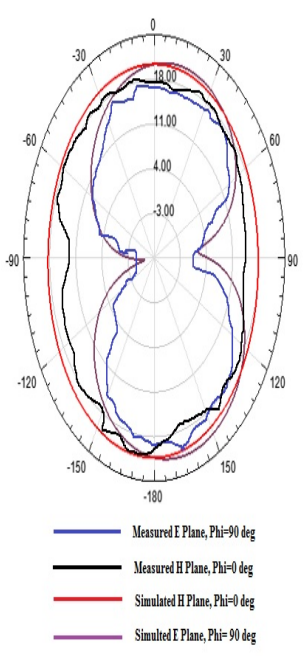

(b) $7.9 \mathrm{GH}$
Figure 10 Simulated and measured E field radiation patterens at (a) $5.7 \mathrm{GHz}$ and (b) $7.9 \mathrm{GHz}$

The simulated and measured values of gain versus frequency are shown in Figure 11 over 5-11 GHz frequency range. The gain starts gradually to increase from $5 \mathrm{GHz}$ until reaches the peak value of $(4.3 \mathrm{~dB}$ in the simulation and $4.1 \mathrm{~dB}$ in the measurement) at 9GHz. Then, it gradually decreases until 11 $\mathrm{GHz}$. Both simulated and measured gain results are in fine agreement.

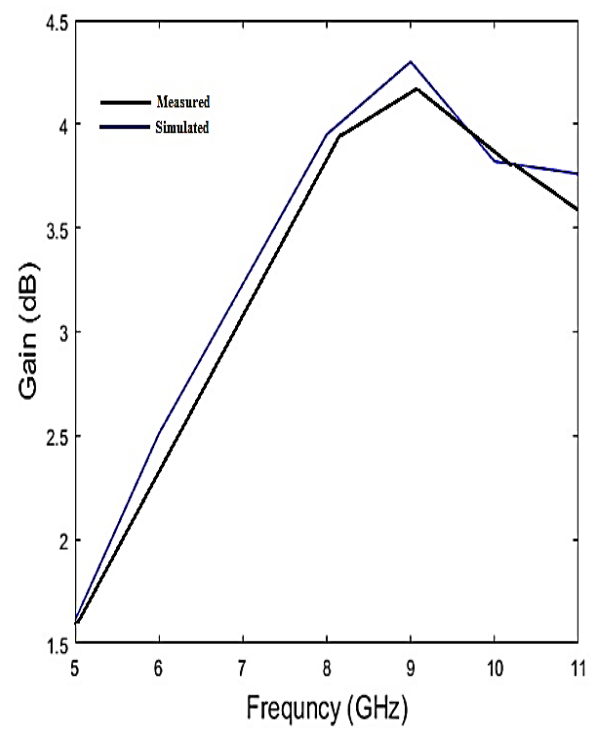

Figure 11 Simulated and measured gains versus frequency 


\section{Conclusions}

A new compact fractal MSA using pentagon slot inside circular patch resonator is proposed to operate at a range of frequencies of (4.5-9.3) GHz. It has been simulated by HFSS software to obtain the best geomatric design and successfully verified by fabrication and measurement. The iterative method is used in this design up to third iteration. The length of ground plane $\mathrm{L}_{\mathrm{g}}$ and the width of feed line $\mathrm{W}_{\mathrm{f}}$ are optimized and it is found that $3 \mathrm{~mm}$ width of feed and $3 \mathrm{~mm}$ length of ground are the best values to get the widest bandwidth. The simulated return loss values are -33 and $-41 \mathrm{~dB}$ at resonant frequencies of 5.7 and $7.9 \mathrm{GHz}$ with gain of $3.2 \mathrm{~dB}$ and impedance bandwidth of $4.8 \mathrm{GHz}$. There are adequte agreement between simulated and measured results in terms of input reflection, far field radiaton patterns and gain. The proposed fractal MSA has highly compact FR4 substrate size of $(20 \times 18) \mathrm{mm}^{2}$ that is appropriate for wideband applications as in weather radar, satellite communication and $\mathrm{C}$ band systems.

\section{Acknowledgements}

We would like to thank the staff of microstrip section in the technology and science ministry for their support, and they help us to produce the sample of our research.

\section{References}

[1] Y. S. Mezaal, "New Compact Microstrip Patch Antennas: Design and Simulation Results," Indian Journal of Science and Technology,vol. 9, no. 12, March 2016.

[2] M S. Tripathi, A. Mohan, and S. Yadav, "Hexagonal fractal ultra-wideband antenna using Koch geometry with bandwidth enhancement," IETMicrowaves, Antennas and Propagation, vol. 8, no. 15, pp. 1445-1450, 2014.

[3] Sharma N, Sharma V. A design of Microstrip Patch Antenna using hybrid fractal slot for wideband applications. Ain Shams Engineering Journal (2017), http://dx.doi.org/10.1016/j.asej.2017.05.008.

[4] M. Gupta, V. Mathur, Koch boundary on the square patch microstrip antenna for ultrawideband applications, Alexandria Engineering Journal. http://dx.doi.org/10.1016/j.aej.2017.06.005

[5] Ali J., Abdulkareem S., Hammoodi A., Salim A., Yassen, M., Hussan, M., and Al-Rizzo, H.: Cantor fractal-based printed slot antenna for dual-band wireless applications. International Journal of Microwave and Wireless Technologies, vol. 8, no. $2,2016$.
[6] Hatem Rmili,1 Donia Oueslati, Imen Ben Trad, Jean Marie Floch, Abdullah Dobaie,and Raj Mittra, " Investigation of a Random-Fractal Antenna Based on a Natural Tree-Leaf Geometry", Hindawi International Journal of Antennas and Propagation Volume 2017, Article ID 2084835, 7 pages, https://doi.org/10.1155/2017/2084835.

[7] Rupleen Kaur, Satbir Singh, Naveen Kumar, "A Review of Various Fractal Geometries for Wireless Applications", International Journal of Electrical and Electronics Engineering. Vol. 2, Special Issue, 34-36, 2015.

[8] H. A. Ghali and T. A. Moselhy, "Broad-band and circularly polarized space-filling-based slot antennas," IEEE Transactions on Microwave Theory and Techniques, vol. 53, no. 6, pp. 19461950, 2005.

[9] Nasimuddin, Z. N. Chen, and X. Qing, "Symmetric-apertureantenna for broadband circular polarization," IEEE Transactions on Antennas and Propagation, vol. 59, no. 10, pp. 3932-3936, 2011

[10] B. Hephzibah Lincy, A. Srinivasan, B.Rajalakshmi, "Wideband Fractal Microstrip Antenna for Wireless Application", IEEE Conference on Information \& Communication Technologies (ICT), pp.112-115, Volume 3 No. $3,2013$.

[11] Ammar Nadal Shareef, Ali. A.Seleh, Amer Basim Shaalan, " Pentagon Fractal Antenna for Above $6 \mathrm{Ghz}$ band Applications", International Journal of Applied Engineering Research ISSN 0973-4562 Volume 12, Number 24 (2017) pp. 16017-16023.

[12] Manisha GUPTA, Vinita MATHUR, " Koch fractal-based hexagonal patch antenna for circular polarization", Turkish Journal of Electrical Engineering \& Computer Sciences, pp. 44744485, 03.12.2017, doi:10.3906/elk-1702-295.

[13] Amir Altaf, Youngoo Yang, Kang-Yoon Lee, and Keum Cheol Hwang, Wideband Circularly Polarized Spidron Fractal Slot Antenna with an Embedded Patch, International Journal of Antennas and Propagation, 2017.

[14] Seevan F. Abdulkareem, Jawad K. Ali, Ali I. Hammoodi, Ali J. Salim, Mahmood T. Yassen, and Mohammed R. Hussan, "Fabrication and Performance Evaluation of a Fractal based Slot Printed Antenna for Dual-band Wireless Applications," Iraqi Journal of Computer, Communication and Control Systems Engineering, vol. 14, 2014.

[15] Constantine A. Balanis, Antenna Theory Analysis And Design, $4^{\text {th }}$ edition, John Wiley \& Sons, Inc., 2016.

[16] Eric W. Weisstein, CRC concise encyclopedia of mathematics, CRC Press, 2nd edition, 2003. 
[17] Amini A, Oraizi H, Zadeh MAC. Miniaturized UWB Log-Periodic square fractal antenna. IEEE Antennas and Wireless Propagation Letters, Vol.14:1322-1325, 2015.

[18] Ang, B.-K. andB.-K. Chung, "A widebandEshapedmicrostrip patch antenna for 5-6 GHz wireless communications," Progress In Electromagnetics Research, PIER 75, 397-407, 2007

[19] Sun, L., M. He, J. Hu, Y. Zhu, and H. Chen, “A Butterfly-shaped wideband microstrip patch antenna for wireless communication," International Journal of Antennas and Propagation, Vol. 2015, 8 Pages, Article ID 328208, 2015.

[20] Dawood, SJ, Salari MA, Ghoochani OH. Crossslot antenna with U-shaped tuning stub for ultrawideband applications. International Journal of Antennas and Propagation, 2008. doi: $10.1155 / 2008 / 262981$. 